\title{
Zinc Electrochemical Deposition from Ionic Liquids and Aqueous Solutions Onto indium tin oxide.
}

\author{
F.M. Rivas-Esquivel ${ }^{1,2}$, G.M. Brisard ${ }^{2,}$, R. Ortega-Borges ${ }^{1, *}$, G. Trejo $^{1}$, Y.Meas $^{1}$ \\ ${ }^{1}$ Centro de Investigación y Desarrollo Tecnológico en Electroquímica (CIDETEQ), Parque \\ Tecnológico Querétaro Sanfandila. C.P. 76703 Pedro Escobedo, Qro., México. \\ ${ }^{2}$ Faculté de Sciences, Université de Sherbrooke, 2500, Boulevard de l'Université Sherbrooke, Qc, \\ Canada J1K 2R1 \\ *E-mail: rortega@ cideteq.mx
}

doi: $10.20964 / 2017.03 .58$

Received: 11 November 2016 / Accepted: 20 January 2017 / Published: 12 February 2017

\begin{abstract}
Ionic Liquids (ILs) are classified as green solvents and in this context, ILs offer the possibility to improve the electrodeposition processes of several metals or alloys, without involve the use of hazardous chemicals. In this work, we study the electrodeposition process of metallic zinc from the protic ionic liquid 2-hydroxyethyl ammonium propionate (2-HEAP) and from acidic aqueous solutions on indium tin oxide (ITO) as substrate. Electrodeposits obtained from 2-HEAP by using different zinc salts as a source of metallic ions are compared with electrodeposits obtained from aqueous solutions. Results show the influence of zinc salt and of the reaction media (2-HEAP or aqueous solutions) on the electrochemical reduction process and on the morphological properties of the deposits.
\end{abstract}

Keywords: Zinc electrodeposition, ITO, protic ionic liquids, Zn coatings.

\section{$\underline{\text { FULL TEXT }}$}

(C) 2017 The Authors. Published by ESG (www.electrochemsci.org). This article is an open access article distributed under the terms and conditions of the Creative Commons Attribution license (http://creativecommons.org/licenses/by/4.0/). 